\title{
Systematic review of the impact of food provision on adherence to the tuberculosis treatment
}

\author{
Abourof Rania Hassan ${ }^{1}$ and Mousnad Mohamed Awad ${ }^{2 *}$ \\ ${ }^{1}$ Senior medical representative at Sigma pharmaceutical company Khartoum - Sudan \\ ${ }^{2}$ Faculty of Pharmacy, International University of Africa (IUA), Khartoum, Sudan
}

\begin{abstract} impact' and 'tuberculosis treatment'.

Introduction

Tuberculosis (TB) is major contributor to the global burden of disease and has received considerable attention in recent years, particularly in low- and middle-income countries where it is closely associated with HIV/AIDS [1].

TB is atop infectious disease killer worldwide. In 2014, 9.6 million people fell ill with TB and 1.5 million died from the disease. Over 95 per cent of TB deaths occur in low- and middle-income countries and it is among the top five causes of death for women aged 15 to 44 . The largest number of new TB cases occurred in south-east Asia and the Western Pacific. However, Africa carried the most severe burden, with 281 cases per 100,000 populations in 2014(compared with a global average of 133). Ending the TB epidemic by 2030 is among the health targets of the newly adopted sustainable development goals [2-7].
\end{abstract}

Objective: The aim of this study was to systematically identify the impact of food provision on adherence to tuberculosis treatment.

Methods: A systemic search of published studies was conducted using major widely used electronic databases using the search terms 'food provision', 'adherence

Main results: From a total of 18,040 results, only 11 were included in the full review. The main determinate categories that were indentified in the review were (1) socio economic factors i.e. (lack food ....). (2) Patient related factors. (3) Condition related factors. (4) Health care team and health system factors.

Conclusion: Adherence to the long course of TB treatment is a complex, dynamic phenomenon with a wide range of factors that impact treatment-taking behaviour. The main result identified in the review is that food incentive has a strong positive impact on adherence to tuberculosis treatment.

\section{How to define TB adherence and why it is important?}

The word 'adherence' has replaced 'compliance' in much of the medical literature. Patient adherence has been defined by the World Health Organization (WHO) as the extent to which person's behaviour-e.g. taking medication, attending follow-up-corresponds with recommendations from a healthcare provider which have been agreed upon by the individual.

The issue of adherence to TB care is different from that of other chronic disease like diabetes, as the goal of care is not only to cure the individual patient, but also to prevent the transmission of infection; therefore adherence to TB treatment and care is a necessity for the health of both the individual patient and his or her community or society.

Unfortunately, there are multiple factors that can affect adherence to TB treatment. This study attempts to systematically review the published literature regarding the impact of food provision on adherence.

\section{General objective}

The main factors that affecting the adherence of tuberculosis treatment.

\section{Specific objective}

The impact of food on adherence to tuberculosis treatment.

\section{Material and methods}

This review was performed using an adaptation of the Cochrane guidelines for systematic reviews of health promotion and public health.

\section{Criteria used to consider reviews for inclusion}

The objective of this study is to determine only the impact of food provision on adherence to the treatment of tuberculosis-i.e. whether there is any relationship between provision of food and patient adherence to the treatment.

The studies reviewed needed to have following characteristics:

1. The main objective is to explore the impact of food provision on adherence to TB treatment.

2. The study must measure factors that affect treatment adherence.

3. The study must be written in English.

${ }^{*}$ Correspondence to: Mousnad Mohamed Awad, Assistant Professor, Faculty of Pharmacy, International University of Africa (IUA), Khartoum, Sudan, Tel: +249-912325864; E-mail: m_abdalaziz@yahoo.com, mousnad@gmail.com

Keywords: Impact, adherence, tuberculosis treatment

Received: May 16, 2019; Accepted: June 25, 2019; Published: June 28, 2019 
4. The full study is available.

Research articles that were published as reviews, commentaries and letters were excluded from review.

\section{Study instrument and tools}

A systemic search of published studies was conducted using major widely used electronic databases using the search terms 'food provision', 'adherence impact' and 'tuberculosis treatment'.

The major electronic databases were :( Pub Med, Science Direct, Springer link, Google Scholar and Medline). The study used the time frame from 2004 to 2014 (Figure 1).

\section{Operational definition of variables}

(1) Dependant variable: adherence to tuberculosis

(2) Independent variable: food provision.

\section{Data management and statistical analysis}

A pre- developed data abstraction form was used to extract the title, author, country, year, objective(s), and the methods used to assess the impact of food provision on adherence to the tuberculosis treatment.

Narrative synthesis was used in this review. Meta-analysis was deemed to be unsuitable because of the heterogeneity of the studies in terms of method, setting and outcome.

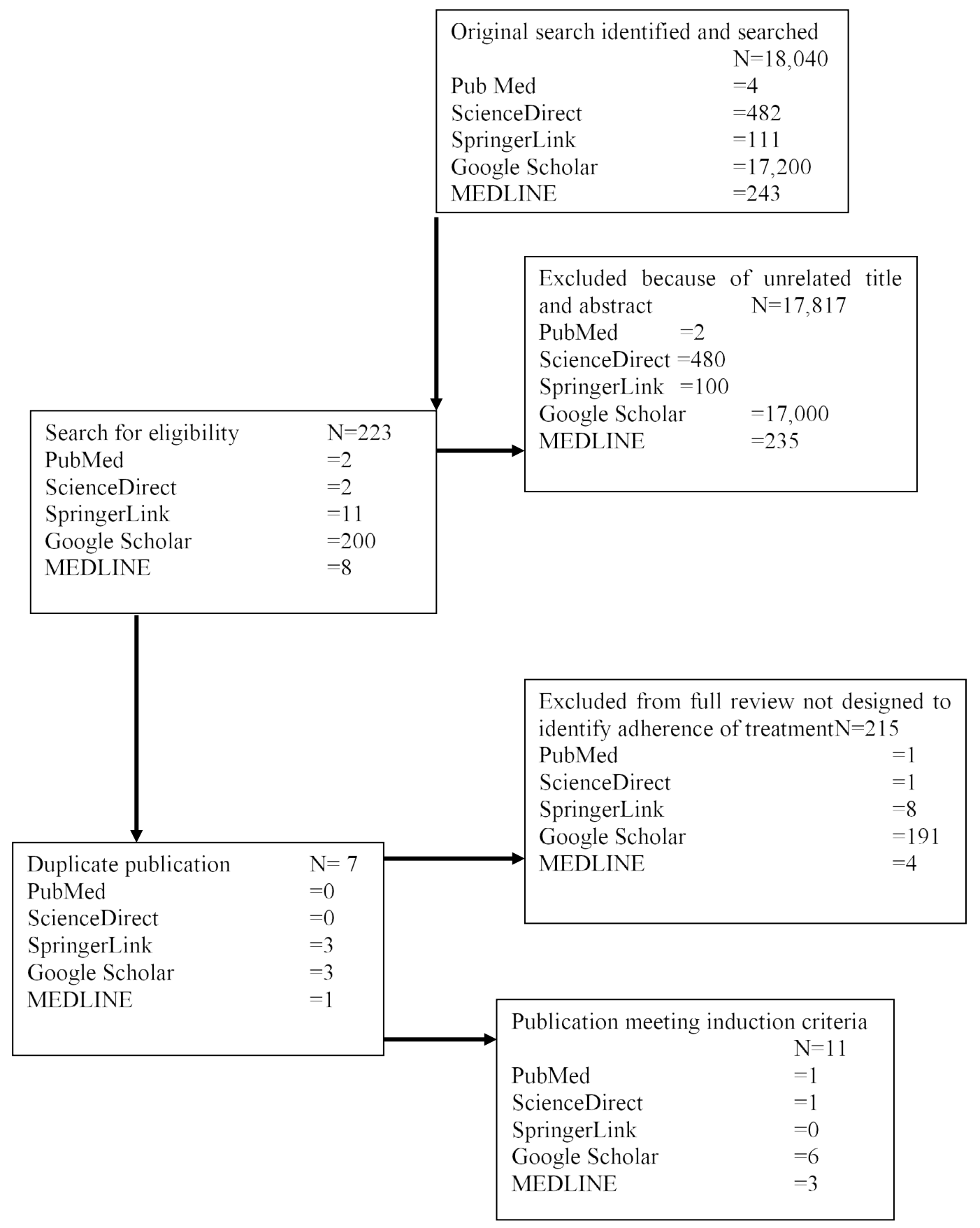

Figure 1. Process of determining study eligibility 
The synthesis steps began with the organization of the extracted data by the author.

A narrative description of the most common factors identified from the review is reported and discussed in the results and discussion sections.

\section{Results}

\section{Description of the included reviews}

Figure 1 shows the studies that were included in the systematic review and the reasons for the exclusion of others. Out of 18,040 studies, only 11 studies met the inclusion criteria and were included in the review. All of the studies included were from developing countries: South Africa (4), Ethiopia (1), Zambia (2), Russia (1), Brazil (1), Bolivia (1) and multinational (1).

\section{Characteristics and methodological aspects of the included reviews}

Table 1 shows the different study designs that were included in this review. None of the studies was a randomized controlled trial (RCT) or a clinical controlled trial. They included retrospective observational studies, a repeated cross-sectional study and qualitative and quantitative studies.

\section{Factors affecting adherence to tuberculosis treatment}

A summary of the statistically significant factors affecting adherence to tuberculosis treatment in the review is presented in Table 2 . The most common factors that affect adherence to tuberculosis treatment are socio-economic factors, including lack of food (poverty).

Most of these studies concentrated on food provision and other factors that can improve adherence to the treatment.

All of these studies assess the impact of food provision as having the capacity to improve adherence to treatment. An incentive in the form of food had a strong positive impact on adherence to drug treatment. In all 11studies, lack of food is mentioned as one of the most important factors that can lead to non-adherence to treatment.

Food incentives are attractive because of the well described link between malnutrition and tuberculosis.

\section{Discussion}

This study attempted to explore systematically the influence of food provision on adherence to TB treatment. Studies that examined adherence or non-adherence to TB treatment were included. Several factors have been identified that significantly affect adherence to treatment. Many studies focused on the influence of socio-economic factors such as poverty, lack of social support and unemployment on adherence of tuberculosis treatment [8-17] (Table 2).

In these studies, it was found that provision of supplementary food acts as one of the enabling factors to assist patient adherence and completion of treatment.

Patients' adherence to their medication regimens was influenced by the interaction of a number of factors, as shown in Table 3 .

Table 1. General characteristics and methods of the included studies

\begin{tabular}{|c|c|c|c|}
\hline No. & Authors & Country & Study design \\
\hline 1 & Ana lucia, et al. (2006) & Brazil & Cross sectional survey \\
\hline 2 & Cremers, et al. (2014) & Zambia & Quantitative and qualitative methods \\
\hline 3 & Finaly, et al. (2012) & South Africa & Retrospective case control study \\
\hline 4 & Garden, et al. (2013) & Russia & Study group/control group \\
\hline 5 & Govenders and Mash (2009) & South Africa & Case control study \\
\hline 6 & Gebremariam, et al. (2010) & Ethiopia & Qualitative study \\
\hline 7 & Koona, et al. (2004) & Zambia & Cross sectional study \\
\hline 8 & Martin (2006) & Bolivia & qualitative methods/in depth interviews \\
\hline 9 & Martins, et al. (2008) & South Africa & Qualitative research \\
\hline 10 & Naidoo, et al. (2008) & South Africa & Qualitative analysis research \\
\hline 11 & Richter, et al. (2014) & Multinational & Technical review panel \\
\hline
\end{tabular}

Table 2. Significant factors affecting adherence to tuberculosis treatment

\begin{tabular}{|c|c|c|}
\hline & Authors & Factors affecting patient adherence to $\mathrm{TB}$ treatment \\
\hline 1 & Ana lucia, et al. (2006) & Lack of food and lack of financial support. \\
\hline 2 & Cremers, et al. (2014) & $\begin{array}{l}\text { Lack of food, lack of follow-up, lack of counselling, lack of cooperation between hospital and patient, and structural obstacles like queues, } \\
\text { clinic. }\end{array}$ \\
\hline 3 & Finaly, et al. (2012) & $\begin{array}{l}\text { Lack of effective incentive (food incentive) and financial support, lack of social assistance programmes, lack of community participation, } \\
\text { lack of programme supervision and management and lack of clinical follow-up. }\end{array}$ \\
\hline 4 & Garden, et al. (2013) & Lack of food incentive (food has a strong positive impact on adherence to TB drug treatment). \\
\hline 5 & Govenders and Mash (2009) & $\begin{array}{l}\text { Socio-economic factors (poverty, high cost of medication); patient related factors (cultural beliefs about illness and ethnicity); healthcare } \\
\text { team and health system factors (inadequate relationship between patient and providers, healthcare providers are unsupportive); condition } \\
\text { related factors (asymptomatic patient, side effects of medication). Defaulting from treatment was associated with lack of food. }\end{array}$ \\
\hline 6 & Gebremariam, et al. (2010) & Lack of food and financial support. \\
\hline 7 & Koona, et al. (2004) & $\begin{array}{l}\text { Feeling better }(45 \%) \text {, running out of TB drugs }(25 \%) \text {, knowledge on benefits of completing treatment }(25 \%) \text {, TB drugs are too strong }(20 \%) \\
\text { and lack of food }(15 \%) \text {. }\end{array}$ \\
\hline 8 & Martin (2006) & Lack of food (food acts as one of the enabling factors to assist patients to adhere and complete treatment). \\
\hline 9 & Martins, et al. (2008) & $\begin{array}{l}\text { Socio-economic factor (poverty); knowledge of tuberculosis and inability of health service provider to provide patient with easy access to } \\
\text { the service; food security; social support; satisfaction with the hospital; method of transportation; time taken to travel and income. }\end{array}$ \\
\hline 10 & Naidoo, et al. (2008) & Social and economic factors (poverty, lack of food) and cultural factors. \\
\hline 11 & Richter, et al. (2014) & Lack of food (food and nutritional support improve treatment uptake and adherence). \\
\hline
\end{tabular}


Table 3. Factors identified from the literature review that effect adherence to tuberculosis

\begin{tabular}{|c|c|c|c|}
\hline \multicolumn{2}{|c|}{ Category } & \multirow{2}{*}{$\begin{array}{l}\text { Factors } \\
\text { - Poverty, lack of food } \\
\text { - Unemployment } \\
\text { - Lack of social support } \\
\text { - Cost of transport, income }\end{array}$} & \multirow{2}{*}{$\begin{array}{l}\text { Reference } \\
{[8-17]}\end{array}$} \\
\hline 1) & Socio-economic factor & & \\
\hline 2) & Patient-related factors & $\begin{array}{l}\text { - Ethnicity, gender } \\
\text { - Cultural beliefs about illness }\end{array}$ & {$[11,12,18]$} \\
\hline 3) & Condition-related factors & $\begin{array}{l}\text { - Asymptomatic patient } \\
\text { - Complex treatment regimen } \\
\text { - Adverse effect of medication } \\
\text { - Lack of hope to live } \\
\text { - Feeling better } \\
\text { - Running out of TBdrugs at home }\end{array}$ & {$[11,13-15]$} \\
\hline 4) & Healthcare team and health system factors & $\begin{array}{l}\text { - Poorly developed health service } \\
\text { - Inadequate relationship between healthcare providers and patients } \\
\text { - Healthcare providers are unsupportive }\end{array}$ & {$[9,15,17,18]$} \\
\hline
\end{tabular}

\section{Summary}

In these studies, it was found that provision of supplementary food acts as one of the enabling factors to assist patient adherence and completion of treatment.

Patients' adherence to their medication regimens was influenced by the interaction of a number of factors, as shown in Table 3 . The generally findings from these articles showed that patients who had food support, emotional support and help from family members, friends or a health provider were more likely to be compliant to the treatment.

The influence of food on treatment adherence was apparent in all included studies [8-17].

In this synthesis, socio-economic factors are discussed in various ways, with poverty remaining one of the most important factors for treatment taking, especially when linked to healthcare service factors such as poor accessibility, poor equipment and distant clinics.

\section{Study key findings}

Among all factors that can affect adherence to TB treatment, we found that provision of food had a strong positive impact on adherence to TB drug treatment.

\section{Conclusion}

Adherence to a long course of TB treatment is a complex, dynamic phenomenon with a wide range of factors that impact on treatment taking behaviour. The results of this review illustrate the impact of food provision on adherence to the tuberculosis treatment.

Available studies indicate that in most cases, enablers in the form of food assistance improve TB treatment adherence. Delivering food to patients with TB has two purposes: one is to improve nutritional status, and the other to improve adherence to the treatment.

Patients' adherence to their medication regimens was influenced by the interaction of a number of factors, one of which was lack of food, and we found that a food incentive had a strong positive impact on adherence to TB drug treatment. In conclusion, provision of food to tuberculosis patients improves adherence to the treatment and therefore reduces cases of drug resistance.

\section{Implications and study recommendations}

Adherence to $\mathrm{TB}$ treatment is a necessity for the care of both the individual and society. It is very important for policy makers to understand the need for interventions to address barriers and facilitators to treatment adherence

It is sensible for the policy maker to address the following.

1) Encourage treatment adherence by providing food or other life support at the individual, household, and community levels as a way of improving recovery and preventing increased drug resistance.

2) Support food assistance and food aid with greater emphasis on nutritional status and on protecting the contacts of tuberculosis patients.

3) Improve nutritional status by ensuring food security, especially at the household level, including adequate micronutrients intake.

4) Micronutrients intake can be increased through the use of fortified foods, lipid based nutrient supplements and micronutrient powders if given other food, although, as noted, further work on this continues and further clarity is needed on the best combinations and dosage.

5) Treat malnutrition in active tuberculosis cases according to guidelines for undernourished adults and, as is increasingly being undertaken for HIV individuals, to reduce mortality and promote recovery.

\section{Study limitations}

There are some limitations to this review.

A small number of studies were found to meet the review inclusion criteria. None of the included studies were conducted in developed countries-the findings are therefore most applicable to low and middle income countries that carry the greatest burden of $\mathrm{TB}$ and where interventions to improve treatment adherence and completion are needed urgently.

\section{Contribution of the findings}

The findings may help health policy makers to understand the need for a food incentive to improve patient adherence to the treatment and therefore decrease the number of MDR (multi drug resistant) TB patients. This is a form of TB caused by bacteria that do not respond to at least the two most powerful first line anti-TB drugs. The primary cause of MDR TB is inappropriate or incorrect use of anti-TB drugs.

TB programme managers frequently assume that a willingness to adhere must be instilled in a patient in order to improve adherence rates. The synthesis found that even where patients are willing to adhere; socio-economic factors such as poverty may prevent them from doing so. 
In order to support people with TB during their treatment, policymakers must appreciate that $\mathrm{TB}$ affects all aspects of patients' lives and poor adherence to TB therapy is the most common cause of initial treatment failure and of disease relapse, which in turn contributes to patient morbidity, mortality, the transmission of the disease to others and the development of drug resistance. Adherence to TB treatment is a necessity for the care of both the individual and society.

\section{Future research}

Based on the findings of this synthesis, we believe that further research is needed to understand people's experience of TB and its treatment, and to develop more patient centred approaches to improve treatment adherence among people with TB.

Efforts to improve treatment outcomes require a better understanding of the particular barriers to and facilitators of adherence to TB treatment, and of the patient experience of taking treatment.

Other questions identified that need addressing, given the current emphasis on treatment adherence, were the following.

(1) How much nutrition intervention impacts on treatment outcomes?

(2) The impact of improved nutrition, usually through food assistance, on nutrient intake and dietary diversity.

(3) Whether close contacts should also be targeted-to improve nutritional status and hence resistance-and if so, with what kind of support-e.g. indirect income transfers as in a conditional cash transfer, micronutrient supplements, food assistance-to reduce the risk of tuberculosis infection.

(4) Amore critical look is needed at the nutritional value of the food support provider.

\section{Acknowledgement}

This review was a part of thesis in the fulfilment of the requirement for the degree of master at Khartoum university.

I would like to thank DR: MOHAMMED AWAD MOUSNAD for his valuable advice and helpful comments in this review.

\section{References}

1. Dye C (2006) Global epidemiology of tuberculosis. Lancet 367: 938-940. [Crossref]

2. http://www.stoptb.org/wg/mdrtb
3. Pamela orr (2011) Adherence to tuberculosis care in CanadianAboriginal populations Part 1: definition, measurement, responsibility, barriers. International journal of circumpolar health, Canada 2: 113-127.

4. https://www.theunion.org/what-we-do/technical-assistance/tuberculosis-and-mdr-tb/ multidrug-resistant-tb-mdr-tb

5. Armstrong R, Water E, Jackson N, Oliver S, Popay J, et al. (2007) Guidelines for systematic review of health promotion and public health intervention.

6. Salla A. Munro, Simon A, Lewin, Helen J, et al. (2007) Asystematic review of qualitative research of patient adherence to tuberculosis treatment. Plos medicine journal p. 1 .

7. Martin W, Bloem, Saskia de Pee (2010) Nutrition and food insecurity in relation to HIV/AIDS and TB, international nutrition foundation for the united nation university p: 71.

8. Bodil Garden, Arina Samanina, Amanda Ovregarad (2013) Food incentives improve adherence to tuberculosis drug treatment among homeless patients in Russia: scandivian journal of caring science p: 120-121.

9. Alyssa Finaly, Joey Lancaster (2012) Patient and provider level risk factors associated with default from tuberculosis treatment in South Africa: BMC biomedical center health $\mathrm{p}: 10$.

10. Linda M. Richter, Knut Lonnroth (2014) Economic support to patients in HIV/TB grants in rounds 7 and 10 from the global fund to fight AIDS, tuberculosis and malaria: PLOS journal p: 6-8.

11. Martins N, Grace J (2008) An ethnographic study of barriers to and enabling factors for tuberculosis treatment adherence in Timor Leste. Int J Tuberc Lung Dis 12: 534-537.

12. Pamela Naidoo, Judy Dick, Dian Coopel (2008) Exploring tuberculosis patient adherence to treatment regimen and prevention program at public health site. $S A G E$ journals 19: 55-70.

13. Marcia TCT, Belo, Lia Selig, Ronir Raggio Luiz (2006) Choosing incentives to stimulate tuberculosis treatment compliance in a poor county in Rio de Janeiro state, Brazil: Med sci monit 12: 1-5

14. Fredrick A. D.Koona, Mary Tuba (2004) An assessment of factors contributing to treatment adherence and knowledge of tuberculosis transmission among patients on tuberculosis treatment. BMC public health 4: 68 .

15. Govenders S, Mash R (2009) What are the reasons for patients not adhering to their anti-tuberculosis treatment in South Africa? SA fam pract 51: 512-516.

16. Mekdes K, Gebremariam, Gunnar A, Bjune (2010) Barriers and facilitators of adherence to TB treatment in patients on concomitant TB and HIV treatment: $B M C$ public health 10: 56

17. Cremers AL, Kapata N (2014) Assessing key influence factors on patient adherence and compliance for the implementation of a tuberculosis control program in Lusaka, Zambia. International journal of infectious diseases pp. 1-460.

18. Nelson ES, Martin (2006) Transdisciplinary research documenting the introduction of the DOTS strategy and investigating factors contributing to patient's adherence to tuberculosis treatment pp. 148-149.

Copyright: (C2019 Hassan AR. This is an open-access article distributed under the terms of the Creative Commons Attribution License, which permits unrestricted use, distribution, and reproduction in any medium, provided the original author and source are credited. 